\title{
Oral Health Knowledge, Attitude, and Practices among Postgraduate Students of Panjab University, Chandigarh: A Cross-sectional Study
}

\author{
Leena Verma ${ }^{1}$, Sidhi Passi ${ }^{2}$, Urvashi Sharma ${ }^{3}$, Jyoti Gupta ${ }^{4}$
}

\begin{abstract}
Background: Dental caries and periodontal diseases are the most commonly occurring dental problems. Proper knowledge, attitude, and practices (KAPs) of oral health of young adults will help in prevention of these diseases.

Aim: To comparatively evaluate the oral health KAPs related to oral health of postgraduate students of Panjab University, Chandigarh, with respect to gender and different departments.

Setting and design: A descriptive cross-sectional survey was conducted using a questionnaire that assessed KAPs of postgraduate students, aged 17-25 years.

Materials and methods: This survey was undertaken on 600 postgraduate students of Panjab University, Chandigarh. The sample was divided into 3 groups: group I-arts students $(n=200)$, group II—science students $(n=200)$, and group III—commerce students $(n=200)$. Data were collected and subjected to statistical analysis.

Statistical analysis used: Chi-squared test was used for comparison between different groups. ANOVA and Kruskal-Wallis compared the data between different departments, and Mann-Whitney $U$ test between males and females.

Results: The students of arts had significantly lesser knowledge of oral health compared with other departments. About $65 \%$ arts students believed that sweets/soft drinks/chips were causing tooth decay compared with $83 \%$ science and $80 \%$ commerce students ( $p$ value $<0.001$ ). About $52.5 \%$ arts students had knowledge that blood on the toothbrush was indicative of gum disease followed by $67 \%$ science and $76 \%$ commerce students ( $p$ value $<0.001$ ).

Conclusion: In our study, there was no significant difference in gender with respect to KAPs of oral health but a significant difference was observed among different departments with arts students showing significantly lesser knowledge.

Keywords: Attitude, Knowledge, Oral health, Questionnaire, Students.

International Journal of Clinical Pediatric Dentistry (2020): 10.5005/jp-journals-10005-1717
\end{abstract}

\section{INTRODUCTION}

Oral health is significantly associated to an individual's KAPs. In recent times, the incidence of oral diseases has decreased significantly because of fewer intakes of sugary products and increased use of oral hygiene aids. ${ }^{1}$ Several studies have evaluated KAPs with different results. ${ }^{1-3}$ The results obtained from the studies regarding changes in oral health behavior help in planning, implementation, and evaluation of oral health promotion programs.

Taking into consideration the importance of college students as being the cornerstone of any civilized community, this study was done for the purpose of determining oral health KAPs among gender and different departments of postgraduate students of Panjab University in Chandigarh city.

Based on the results of students, health education programs should be designed for enhancing their KAPs toward oral health and make them aware of the most common oral diseases, that is, dental caries and periodontal disease.

\section{Materials and Methods}

This cross-sectional survey was undertaken on 600 postgraduate students of Panjab University, Chandigarh, who were in the age group of 17-25 years. This study was ethically cleared by Research Ethics Committee (Protocol nos. 12/24) and granted by DST Chandigarh (No. S\&T/Sanc/11/2011/1158-1163).

\footnotetext{
${ }^{1-3}$ Department of Pedodontics, Dr Harvansh Singh Judge Institute of Dental Sciences, Chandigarh, India

${ }^{4}$ Department of Periodontics, Dr Harvansh Singh Judge Institute of Dental Sciences, Chandigarh, India
}

Corresponding Author: Leena Verma, Department of Pedodontics, Dr Harvansh Singh Judge Institute of Dental Sciences, Chandigarh, India, Phone: +91 9501030279, e-mail: drleenaverma32@rediffmail.com

How to cite this article: Verma L, Passi S, Sharma U, et al. Oral Health Knowledge, Attitude, and Practices among Postgraduate Students of Panjab University, Chandigarh: A Cross-sectional Study. Int J Clin Pediatr Dent 2020;13(2):113-118.

Source of support: Department of Science and Technology, Chandigarh (Sanction no. S\&T/Sanc/11/2011/1158-1163)

Conflict of interest: None

A random sampling method was used to select the participants. Proportion allocation was used to select the sample size to get a level of 0.05 and power of 0.95 , and the minimum sample size was calculated as 328. Our sample was 600 participants to avoid any possible dropouts.

A questionnaire was designed to include KAPs regarding oral health. Three dental experts independently evaluated the questionnaire. The validity was checked using Cronbach's alpha and was $>0.7$ in all the dimensions tested. The value of Cronbach's 
alpha was 0.720 for knowledge, 0.703 for attitude, and 0.707 for practice. The questionnaire was distributed to all the students to fill it up. Children who did not give consent to participate were excluded from the study.

The sample was divided into 3 groups:

Group I-arts students ( $n=200)$

Group II-science students $(n=200)$

Group III-commerce students $(n=200)$

The questionnaire consisted of the following:

- Demographic details: the age, sex, and name of the department were recorded.

- Oral health knowledge: questions related to knowledge of caries and gum disease were included. The knowledge about plaque, calculus, fluoride, its benefits, and role in preventing caries was assessed.

- Oral health attitude: these included questions regarding the frequency and purpose of dental visits and the reasons for not visiting a dentist. The attitude of students towards dental diseases was assessed.

- Oral health practices: questions regarding the brushing frequency and the use of a fluoridated toothpaste were asked.

\section{Data Analysis}

All statistical analyses and data management were performed using the Statistical Package for Social Sciences 19.0 (SPSS Inc., Chicago, IL, USA) for Windows and MS-Excel (Microsoft Office 2010). Chi-square test was used for data analysis. A $p$ value of $<0.05$ was considered statistically significant. ANOVA and Kruskal-Wallis test were used for comparing data between different department students (arts, science, and commerce) and Mann-Whitney for a comparison of KAP between males and females.

\section{Results}

A total of 600 postgraduate students from arts, science, and commerce departments were considered. Of these, 200 students were from arts, 200 from commerce, and 200 from science. About 43.7\% ( $n=262)$ were males and $56.3 \%(n=338)$ were females. Of the total students, $55.7 \%(n=334)$ were in the age range of $23-25$ years, $36.7 \%(n=220)$ in the age range of $21-22$ years, and only $7.7 \%(n=46)$ were reported in the age range of $17-20$ years (Table 1).

A significant difference was seen in arts, science, and commerce students in the question that if the tooth is painful then extraction is the only possible treatment. About $47 \%$ arts students believed that extraction is the only possible treatment if the tooth is painful in contrast to $20.5 \%$ science and $26.5 \%$ commerce students, and the difference was statistically significant $(p<0.001)$. When comparison was done for the same question between males and females, the difference was statistically significant $(p<0.001)$ (Table 2).

Table 1: Showing demographic details of the subjects

\begin{tabular}{lcc}
\hline Characteristics & Percentage & Number of cases \\
\hline Gender & & \\
Males & 43.7 & 262 \\
Females & 56.3 & 338 \\
AGE range of subjects & & \\
23-25 years & 55.7 & 334 \\
$21-22$ years & 36.7 & 220 \\
$17-20$ years & 7.7 & 46 \\
\hline
\end{tabular}

A significant difference was seen between males and females and between 3 groups (arts, science, and commerce) regarding knowledge about plaque and calculus (Table 2). About $53.5 \%$ commerce students knew about plaque as soft deposits on the teeth compared to arts (17\%) and science (37.5\%) students ( $p<$ 0.001). However, the knowledge of plaque between males and females was statistically not significant ( $p$ value 0.137 ). Similarly, the knowledge about calculus was statistically significant $(p<0.001)$ between students of different departments and was found most in commerce $21.5 \%$ followed by science (18\%) and the least among arts students (5\%). Males had significantly more knowledge about calculus compared with females ( $p<0.001)$.

The knowledge of fluoride was significantly more in $58.5 \%$ science students followed by $49.5 \%$ commerce and $23 \%$ arts students $(p<0.001)$ but was insignificant with respect to gender ( $p$ value 0.572 ).

Between postgraduate students of different departments, a significantly higher number of commerce students $28 \%$ compared with $23 \%$ science and $14 \%$ arts students knew the benefits of fluoride that it prevented tooth from decay and the result was statistically significant $(p<0.001)$. For the same criteria when comparison was done among males and females, $27.2 \%$ females were having correct knowledge compared with $14.5 \%$ males, and the result was statistically significant ( $p$ value $<0.001$, Table 2 ).

On evaluating the knowledge of postgraduate students toward oral health, only $21 \%$ commerce students believed that the purpose of brushing was to prevent caries in contrast to $23.5 \%$ arts and $26 \%$ science students ( $p$ value $<0.001$ ). Females $(26.9 \%$ ) had significantly more knowledge than males (19.1\%), and the difference was statistically significant ( $p$ value 0.002 , Table 2 ).

Knowledge pertaining to oral health was not good in arts children as compared to science and commerce students as $65 \%$ arts students believed that sweets/soft drinks/chips were responsible for causing caries compared with $83 \%$ science and $80 \%$ commerce students, and the difference was statistically significant $(p<0.001)$. An insignificant difference was seen between males and females with respect to the same question ( $p$ value 0.884 , Table 2 ).

A finding that blood on the toothbrush is suggestive of gum disease was correctly stated by students of commerce (76\%) followed by science $(67 \%)$ and $52.5 \%$ arts ( $p$ value $<0.001$, Table 2 ). Males $(71.4 \%)$ were more correct in identification of this sign than females $(60.4 \%)$ ( $p$ value 0.001$)$.

With respect to the number of previous visits to the dentist during the last 12 months, no significant difference was observed between different department students ( $p$ value 0.11 ), but significant results were seen among males/females ( $p$ value 0.004 Table 3).

Of the commerce students, $34.5 \%$ visited a dentist when there was trouble/pain with teeth/gums compared to science (29\%) and arts $(19.5 \%)$, and the result was statistically significant ( $p$ value $<$ 0.001 , Table 3). More females (33.1\%) visited the dentist in similar conditions than males (20.6\%), and the difference was statistically significant ( $p$ value $<0.001$ )

Of the commerce students, $28 \%$ did not visit the dentist because of fear, which was less in arts and science groups, $13.5 \%$ and $14.5 \%$, respectively ( $p$ value 0.002 , Table 3 ). Furthermore, a statistically significant difference in males/females was observed ( $p$ value $<0.000)$

Preventive oral hygiene practice was judged by the frequency of tooth brushing. About $48.5 \%$ from arts, $48.5 \%$ from science, 
Table 2: Responses related to oral health knowledge according to gender and department

\begin{tabular}{|c|c|c|c|c|c|c|c|c|}
\hline \multirow[b]{2}{*}{ Questions } & \multirow[b]{2}{*}{ Options } & \multicolumn{4}{|c|}{ Department } & \multicolumn{3}{|c|}{ Gender } \\
\hline & & Arts & Science & Commerce & $p$ value & Male & Female & $p$ value \\
\hline \multirow{2}{*}{$\begin{array}{l}\text { If your tooth is very } \\
\text { painful, do you think that } \\
\text { extraction is the only } \\
\text { desired therapy }\end{array}$} & Yes & $47.0 \%(94)$ & $20.5 \%(41)$ & $26.5 \%(53)$ & $<0.001$ & $45 \%(118)$ & $20.7 \%(70)$ & $<0.001$ \\
\hline & No & $53 \%(106)$ & $79.5 \%(159)$ & $73.5 \%(147)$ & & $55 \%(144)$ & $79.3 \%(268)$ & \\
\hline \multirow{2}{*}{$\begin{array}{l}\text { Do you know about } \\
\text { plaque }\end{array}$} & Yes & $17 \%(34)$ & $37.5 \%(75)$ & $53.5 \%(107)$ & $<0.001$ & $39.3 \%(103)$ & $33.4 \%(113)$ & 0.137 \\
\hline & No & $83 \%(166)$ & $62.5 \%(125)$ & $46.5 \%(93)$ & & $60.7 \%(159)$ & $66.6 \%(225)$ & \\
\hline \multirow{2}{*}{$\begin{array}{l}\text { Do you know about } \\
\text { calculus }\end{array}$} & Yes & $5 \%(10)$ & $18 \%(36)$ & $21.5 \%(43)$ & $<0.001$ & $20.6 \%(54)$ & $10.4 \%(35)$ & $<0.001$ \\
\hline & No & $95 \%(190)$ & $82 \%(164)$ & $78.5 \%(157)$ & & $79.4 \%(208)$ & $89.6 \%(303)$ & \\
\hline \multirow{2}{*}{$\begin{array}{l}\text { Do you know about } \\
\text { fluoride }\end{array}$} & Yes & $23 \%(46)$ & $58.5 \%(117)$ & $49.5 \%(99)$ & $<0.001$ & $42.4 \%(111)$ & $57.6 \%(151)$ & 0.572 \\
\hline & No & $77 \%(154)$ & $41.5 \%(83)$ & $50.5 \%(101)$ & & $44.7 \%(151)$ & $55.3 \%(187)$ & $<0.001$ \\
\hline \multirow{4}{*}{$\begin{array}{l}\text { Main advantage of } \\
\text { fluoride is }\end{array}$} & Whitens teeth & $11 \%(22)$ & $29.5 \%(59)$ & $25 \%(50)$ & $<0.001$ & $25.6 \%(67)$ & $18.9 \%(64)$ & \\
\hline & Protects tooth decay & $14 \%(28)$ & $23 \%(46)$ & $28 \%(56)$ & & $14.5 \%(38)$ & $27.2 \%(92)$ & \\
\hline & Protects gums & $6 \%(12)$ & $5.5 \%(11)$ & $3 \%(6)$ & & $4.2 \%(11)$ & $5.3 \%(18)$ & \\
\hline & Don't know & $69 \%(138)$ & $42 \%(84)$ & $44 \%(88)$ & & $55.7 \%(146)$ & $48.5 \%(164)$ & \\
\hline \multirow{5}{*}{$\begin{array}{l}\text { Why do you brush your } \\
\text { teeth }\end{array}$} & To have clean teeth & $67.5 \%(135)$ & $59.0 \%(118)$ & $57.0 \%(114)$ & $<0.001$ & $64.5 \%(169)$ & $58.6 \%(198)$ & 0.002 \\
\hline & Prevent caries & $23.5 \%(47)$ & $26.0 \%(52)$ & $21.0 \%(42)$ & & $19.1 \%(50)$ & $26.9 \%(91)$ & \\
\hline & Prevents bleeding gums & 0 & $3.5 \%(7)$ & $8.5 \%(17)$ & & $2.7 \%(7)$ & $5.0 \%(17)$ & \\
\hline & Prevents oral ulcers & $5.0 \%(10)$ & $1.5 \%(3)$ & $4.0 \%(8)$ & & $5.3 \%(14)$ & $2.1 \%(7)$ & \\
\hline & To get rid of foul odor & $4.0 \%(8)$ & $10.0 \%(20)$ & $9.50 \%(19)$ & & $8.4 \%(22)$ & $7.40 \%(25)$ & \\
\hline \multirow[t]{3}{*}{ Tooth decay is caused by } & Soft drinks/sweets/chips & $65 \%(130)$ & $83 \%(166)$ & $80.0 \%(160)$ & $<0.001$ & $76.7 \%(201)$ & $75.4 \%(255)$ & 0.884 \\
\hline & Fresh fruits & $21.0 \%(42)$ & $13.0 \%(26)$ & $12.0 \%(24)$ & & $14.5 \%(38)$ & $16 \%(54)$ & \\
\hline & Fresh vegetables & $14.0 \%(28)$ & $4.0 \%(8)$ & $8.0 \%(16)$ & & $8.8 \%(23)$ & $8.6 \%(29)$ & \\
\hline \multirow{3}{*}{$\begin{array}{l}\text { Blood on the toothbrush } \\
\text { indicates }\end{array}$} & Gum disease & $52.5 \%(105)$ & $67.0 \%(134)$ & $76.0 \%(152)$ & $<0.001$ & $71.4 \%(187)$ & $60.4 \%(204)$ & 0.001 \\
\hline & Tooth decay & $15.5 \%(31)$ & $13.5 \%(27)$ & $12 \%(24)$ & & $8.0 \%(21)$ & $18.0 \%(61)$ & \\
\hline & Don't know & $32 \%(64)$ & $19.5 \%(39)$ & $12.0 \%(24)$ & & $20.6 \%(54)$ & $21.6 \%(73)$ & \\
\hline
\end{tabular}

and $44 \%$ from commerce departments brushed their teeth twice a day, and the results were not statistically significant ( $p$ value 0.829 , Table 4). But, for the same question, a significant difference was seen between males and females with more females (55.3\%) brushing their teeth twice daily compared with $36.3 \%$ males $(p<0.001)$.

Of the science students, $46 \%$ used fluoridated toothpaste as compared to $21.5 \%$ arts and $42 \%$ commerce students, and the results were statistically significant $(p<0.001$, Table 4$)$. A significant difference between males and females was seen with respect to the use of fluoridated toothpaste (0.002).

Analysis of variance and Kruskal-Wallis test showed that a statistically significant difference in KAP between different departments (Table 5). The scores of knowledge were insignificant with respect to gender ( $p$ value 0.716 ), and statistically significant among different departments ( $p$ value $<0.001$ ) with arts students having lesser knowledge. When comparison was done with respect to attitude, no significant difference was seen between males and females ( $p$ value 0.310 ) but was significant among other departments ( $p$ value 0.002). When practice scores were assessed, a statistically insignificant difference was observed with respect to gender ( $p$ value 0.015) and a significant difference among departments $(<0.001)$.

\section{Discussion}

For any civilized community, the foundation base is laid by the college students and good oral health knowledge in them will lead to better oral health behavior. So, if they have adequate knowledge and good oral health behavior, they can play an important role in the health education of individuals and groups, and act as role models for lay people and the community at large. ${ }^{4,5}$

Caries and gum disease are the two main reasons for loss of teeth. The better the preventive measures taken by an individual, the more the longevity of the teeth and better health. Tooth brushing at least once a day, avoidance of sugary and sticky foods, visiting the dentist for checkups, and use of a fluoridated toothpaste are some of the factors preventing tooth decay.

In the present study, most of the students from different departments were aware that sweets/soft drinks/chips caused dental caries, but the knowledge regarding fluoride, plaque, and calculus was low. These results agreed with studies done by Reddy et al., ${ }^{6}$ Al Subait et al., ${ }^{7}$ and Carneiro et al., ${ }^{8}$ but were different from the ones by Al-Omiri et al. ${ }^{9}$ where majority of the children had knowledge about plaque and calculus. The reason could be the extensive efforts made by the school authorities in 
Table 3: Responses related to oral health attitude according to gender and department

\begin{tabular}{|c|c|c|c|c|c|c|c|c|}
\hline \multirow[b]{2}{*}{ Questions } & \multirow[b]{2}{*}{ Options } & \multicolumn{4}{|c|}{ Department } & \multicolumn{3}{|c|}{ Gender } \\
\hline & & Arts & Science & Commerce & $p$ value & Male & Female & $p$ value \\
\hline \multirow{5}{*}{$\begin{array}{l}\text { How often did you go to } \\
\text { the dentist during the last } \\
12 \text { months? }\end{array}$} & Once & $18 \%(36)$ & $25.5 \%(51)$ & $27 \%(54)$ & 0.11 & $26.7 \%(70)$ & $21.0 \%(71)$ & 0.004 \\
\hline & Twice & $16.5 \%(33)$ & $15.5 \%(31)$ & $18 \%(36)$ & & $11.8 \%(31)$ & $20.4 \%(69)$ & \\
\hline & $\geq 2$ times & $11.5 \%(23)$ & $9 \%(18)$ & $5 \%(10)$ & & $6.1 \%(16)$ & $10.4 \%(35)$ & \\
\hline & $\begin{array}{l}\text { No visit to dentist during last } \\
12 \text { months }\end{array}$ & $39.1 \%(78)$ & $40 \%(80)$ & $34.5 \%(69)$ & & $38.5 \%(101)$ & $37.3 \%(126)$ & \\
\hline & Don't know/don't remember & $15 \%(30)$ & $10 \%(20)$ & $15.5 \%(31)$ & & $16.8 \%(44)$ & $10.9 \%(37)$ & \\
\hline \multirow[t]{4}{*}{$\begin{array}{l}\text { What was the purpose of } \\
\text { your visit? }\end{array}$} & $\begin{array}{l}\text { Appointment was initiated } \\
\text { by dentist }\end{array}$ & $9 \%(18)$ & $8.5 \%(17)$ & $20.5 \%(41)$ & $<0.001$ & $20.2 \%(53)$ & $6.8 \%(23)$ & $<0.001$ \\
\hline & $\begin{array}{l}\text { It was part of follow-up treat- } \\
\text { ment }\end{array}$ & $22.0 \%(44)$ & $24.5 \%(49)$ & $19.0 \%(38)$ & & $16.0 \%(42)$ & $26.3 \%(89)$ & \\
\hline & Pain/trouble with teeth/gums & $19.5 \%(39)$ & $29.0 \%(58)$ & $34.5 \%(69)$ & & $20.6 \%(54)$ & $33.1 \%(112)$ & \\
\hline & Don't know & $49.5 \%(99)$ & $38.0 \%(76)$ & $26.0 \%(52)$ & & $43.1 \%(113)$ & $33.7 \%(164)$ & \\
\hline \multirow{5}{*}{$\begin{array}{l}\text { Reasons for not visiting the } \\
\text { dentist }\end{array}$} & Fear & $13.5 \%(27)$ & $14.5 \%(29)$ & $28.0 \%(56)$ & 0.002 & $22.1 \%(58)$ & $16.0 \%(54)$ & 0.000 \\
\hline & High cost & $15.0 \%(30)$ & $11.0 \%(22)$ & $12.5 \%(25)$ & & $5.3 \%(14)$ & $18.6 \%(63)$ & \\
\hline & No clinic nearby & $8.0 \%(16)$ & $6.5 \%(13)$ & $4.5 \%(9)$ & & $8.8 \%(23)$ & $4.4 \%(15)$ & \\
\hline & No time & $32.5 \%(65)$ & $27.0 \%(54)$ & $21.5 \%(43)$ & & $32.4 \%(85)$ & $22.8 \%(77)$ & \\
\hline & No specific reason & $31.0 \%(62)$ & $41.0 \%(82)$ & $33.5 \%(67)$ & & $31.3 \%(82)$ & $38.2 \%(129)$ & \\
\hline \multirow{4}{*}{$\begin{array}{l}\text { Do you use toothpaste that } \\
\text { contains fluoride? }\end{array}$} & Yes & $21.5 \%(43)$ & $46 \%(92)$ & $42.0 \%(84)$ & $<0.001$ & $39.7 \%$ (104) & $34 \%$ (115) & 0.002 \\
\hline & No & $19 \%(9.5)$ & $12.5 \%(25)$ & $16.5 \%(33)$ & & $10.7 \%(28)$ & $14.5 \%(49)$ & \\
\hline & Don't know & $\begin{array}{l}64.5 \% \\
(129)\end{array}$ & $38.5 \%(77)$ & $39 \%(78)$ & & $43.5 \%(114)$ & $50.3 \%(170)$ & \\
\hline & Don't use toothbrush & $4.5 \%(9)$ & $3 \%(6)$ & $2.5 \%(5)$ & & $6.1 \%(16)$ & $1.2 \%(4)$ & \\
\hline
\end{tabular}

Table 4: Responses related to oral health practices according to gender and department

\begin{tabular}{|c|c|c|c|c|c|c|c|c|}
\hline \multirow[b]{2}{*}{ Questions } & \multirow[b]{2}{*}{ Options } & \multicolumn{4}{|c|}{ Department } & \multicolumn{3}{|c|}{ Gender } \\
\hline & & Arts & Science & Commerce & pvalue & Male & Female & $p$ value \\
\hline \multirow[t]{2}{*}{ Do you brush your teeth? } & Yes & $93.5 \%(187)$ & $89 \%(178)$ & $90 \%(180)$ & 0.2 & $93.9 \%(246)$ & $88.5 \%(299)$ & 0.02 \\
\hline & No & $6.5 \%(13)$ & $11 \%(22)$ & $10 \%(20)$ & & $6.1 \%(16)$ & $11.5 \%(39)$ & \\
\hline \multirow{3}{*}{$\begin{array}{l}\text { How many times do you brush } \\
\text { your teeth? }\end{array}$} & Once a day & $47.5 \%(95)$ & $47.5 \%(95)$ & $50.5 \%(101)$ & 0.829 & $56.5 \%(148)$ & $42.3 \%(143)$ & $<0.001$ \\
\hline & Twice a day & $48.5 \%(97)$ & $48.5 \%(97)$ & $44.0 \%(88)$ & & $36.3 \%(95)$ & $55.3 \%(187)$ & \\
\hline & $\geq 3$ times a day & $4.0 \%(8)$ & $4.0 \%(8)$ & $5.5 \%(11)$ & & $7.3 \%(19)$ & $2.4 \%(8)$ & \\
\hline \multirow{4}{*}{$\begin{array}{l}\text { Do you use your toothpaste that } \\
\text { contains fluoride? }\end{array}$} & Yes & $21.5 \%(43)$ & $46 \%(92)$ & $42 \%(84)$ & $<0.001$ & $39.7 \%(104)$ & $34 \%(115)$ & 0.002 \\
\hline & No & $9.5 \%(19)$ & $12.5 \%(25)$ & $16.5 \%(33)$ & & $10.7 \%(28)$ & $14.5 \%(49)$ & \\
\hline & Don't know & $64.5 \%(129)$ & $38.5 \%(77)$ & $39 \%(78)$ & & $43.5 \%(114)$ & $50.3 \%(170)$ & \\
\hline & Don't use toothpaste & $4.5 \%(9)$ & $3 \%(6)$ & $2.5 \%(5)$ & & $6.1 \%(16)$ & $1.2 \%(4)$ & \\
\hline
\end{tabular}

Table 5: Overall mean scores of KAP according to gender and different departments (mean \pm SD)

\begin{tabular}{llllllll}
\hline Variables & Males & Females & $p$ value & Arts & Science & Commerce & $p$ value \\
\hline Knowledge & $3.83 \pm 1.805$ & $3.891 \pm 0.61$ & 0.716 & $2.91 \pm 0.54$ & $4.21 \pm 0.5$ & $4.3 \pm 1.6$ & $<0.001$ \\
Attitude & $3.12 \pm 1.058$ & $3.13 \pm 0.862$ & 0.310 & $3.26 \pm 0.925$ & $3.1 \pm 0.92$ & $2.9 \pm 0.97$ & 0.002 \\
Practice & $1.50 \pm 0.47$ & $1.60 \pm 0.36$ & 0.015 & $1.70 \pm 0.36$ & $1.5 \pm 0.44$ & $1.5 \pm 0.422$ & $<0.001$ \\
\hline
\end{tabular}

Jordan to improve periodontal knowledge by implementing public awareness programs in the last decade.

More than $50 \%$ of the students from different groups were having knowledge about gum bleeding with $76 \%$ commerce followed by $67 \%$ science and $52.5 \%$ arts students, and the result of intergroup comparison was statistically significant ( $p$ value $<$ 0.001). These finding were in favor of Gupta et al., ${ }^{10} \mathrm{Al}$ Subait et al., ${ }^{7}$ and Bradnock et al., ${ }^{11}$ where also more than $50 \%$ could correlate gum bleeding as indicator of gum disease. A similar statistically significant difference was seen between males and females also. 
A significant difference was seen between males and females and between different department students with respect to the knowledge of use of fluoridated toothpaste and the benefits of fluoride. It was observed that science student's knowledge about fluoride was more as compared to other group students. Similarly, the female students were also aware of fluoride and were using fluoridated toothpaste. The reason could be that both females and science students were more regular with the dental visits and may have followed regular instructions by the dentist to use fluoridated toothpaste, which led to better knowledge about fluorides and its benefits.

Trouble/pain in the teeth/gums was the main reason for the university students to visit the dentists in our study. This was also the main reason for visiting dentist in other studies also. 6,12,13 However, the studies by Al Subait et al. ${ }^{7}$ contrasted with our study where majority visited the dentist before problem arose and were more regular in their routine dental checkups. This shows that the attitude toward dental care was more in the university students of Riyadh, Saudi Arabia, as compared to the university students of Chandigarh. As students of the former were all health professionals, so their knowledge and awareness of dental problems were more than of the subjects of our study who were nonhealth professionals. This could be the reason for a better attitude of Saudi Arabia students toward dental care as compared to our university students.

A statistically significant difference was seen between different department students and between males and females regarding the reasons for visit to the dentist ( $p<0.001$ and $p<0.001$, respectively). This was not in accordance with study done by Gupta et al. ${ }^{10}$ where a statistically insignificant difference between males and females among dental students of different years was seen. The percentage of science and arts students visiting the dentist as a part of follow-up treatment was more compared with the commerce students.

Toothbrushing two times daily was done significantly more by female students compared with males as they were more esthetically conscious about their teeth to look good. This was in corroboration with previous studies, ${ }^{7,14-16}$ which showed better brushing practices among female students as compared to males. However, our study differs from that conducted by Sharda et al. ${ }^{14}$ where no gender difference was found regarding brushing practices. In our study, female students were more particular about their follow-up appointments with the dentists and brushing time frequency.

The present study showed majority of students from arts (48.5\%), science (48.5\%), and commerce (44\%) brushed their teeth twice a day and the differences were statistically insignificant. The percentage of students from different departments brushing twice daily was less than those reported by Jiang et al. ${ }^{17}$ and AI Shammari et al. ${ }^{18}$ where $67 \%$ Chinese adults, $62 \%$ Kuwait adults brushed their teeth, respectively. The difference could be because of social, cultural, environmental, and socioeconomic factors along with certain personal factors such as age, gender, esthetic concern, and interest. However, in our study percentage for brushing frequency was higher as compared to other studies. ${ }^{7,12,19}$

The overall KAPs related to oral health was not significant with respect to gender. This observation was in accordance with the study done by Khami et al., ${ }^{20}$ which showed no gender difference. However, Al Subait et al. ${ }^{7}$ showed a significant difference in gender with respect to KAP.

Though the attitude and practices of arts students was significantly better than those of other departments, the knowledge was significantly less. Factors like education level of students, lack of exposure, and interest in science-related subjects could be a reason for less knowledge in arts students.

The study has some limitations. Firstly, the questionnaire was self-reported by the students. Secondly, the study was limited to a single university. More similar studies should be carried out on larger scale and on a larger sample.

\section{Conclusion}

The results obtained from the study suggest that there was no statistically significant difference in gender with regard to KAPs related to oral health but the knowledge of arts students was significantly less than other department students.

Comprehensive dental education programs should be conducted in different departments of university to enhance the KAPs of students in relation to oral health.

\section{References}

1. Gasgoos SS, Jazrawi KH, Al-Ajrab MG. Dental health knowledge, attitude and behavior among first year university students, Mosul. Al-Rafidain Dent J 2007;7(2):138-152. DOI: 10.33899/rden.2007.8952.

2. Singh S, Pottapinjara S. Dental undergraduate students' knowledge, attitudes and practices in oral health self-care: A survey from a South African university. Afr J Health Prof Educ 2017;9(2):83-87.

3. Astrom AN, Watiti J, Mwangosi E. Knowledge, beliefs and behavior related to oral health among Tanzanian and Ugandan teacher trainees. Acta Odontol Scand 2000;58(1):11-18. DOI: 10.1080/000163500429370.

4. Kassak KM, Dagher R, Doughan B. Oral hygiene and lifestyle correlates among new undergraduate University students Lebanon. J Am Coll Health 2001;50(1):15-17. DOI: 10.1080/07448480109595706.

5. Kumar S, Motwani K, Dak N, et al. Dental health behavior in relation to caries status among medical and dental undergraduate students of Udaipur district, India. Int J Dent Hyg 2010;8(2):86-94. DOI: 10.1111/j.1601-5037.2008.00346.x.

6. Reddy V, Bennadi D, Gaduputi S, et al. Oral health related knowledge, attitude, and practice among the pre-university students of Mysore city. J Int Soc Prev Community Dent 2014;4(3):154-158. DOI: 10.4103/2231-0762.142012.

7. Al Subait A, Ali A, Alehaideb A, et al. Knowledge, Attitudes, and Practices Related to Oral Health among University Students in Saudi Arabia; a Cross-Sectional Study. J Dent Oral Disord 2017;3(6):1080. DOI: 10.26420/jdentoraldisord.2017.1080.

8. Carneiro L, Kabulwa M, Makyao M, et al. Oral health knowledge and practices of secondary school students, Tanga, Tanzania. Int. J Dent 2011;2011:806258. DOI: 10.1155/2011/806258.

9. Al-Omiri MK, Al-Wahadni AM, Saeed KN. Oral health attitudes, knowledge, and behavior among school children in North Jordan. J Dent Educ 2006;70(2):179-187.

10. Gupta S, Saxena S, Sikka N, et al. Oral health attitude, knowledge and behavior of dental students of Jaipur, Rajasthan: A Comparative study. J Indian Assos Public Health Dent 2015;13(4):459-464. DOI: 10.4103/2319-5932.171179.

11. Bradnock G, White DA, Nuttall NM, et al. Dental attitudes and behaviors in 1998 and implications for the future. Br Dent J 2001;190(5):228-232. DOI: 10.1038/sj.bdj.4800935.

12. Farsi JMA, Farghaly MM, Farsi N. Oral health knowledge, attitude and behavior among Saudi school students in Jeddah city. J Dent 2004;32(1):47-53. DOI: 10.1016/j.jdent.2003.08.002.

13. Gopikrishan V, Bhaskar NN, Kulkarni SB, et al. Knowledge, attitude and practices of oral hygiene among college students in Bengaluru city. J Indian Assoc Public Health Dent 2016;14(1):75-79.DOI: 10.4103/2319-5932.178726.

14. Sharda AJ, Shetty S. A comparative study of oral health knowledge, attitude and behaviour of first and final year dental students of Udaipur city, Rajasthan, India. Int J Dent Hyg 2008;6(4):347-353. DOI: 10.1111/j.1601-5037.2008.00308.x. 
15. Polychronopoulou A, Kawamura M, Athanasouli T. Oral self-care behavior among dental school students in Greece. J Oral Sci 2002;44(2):73-78. DOI: 10.2334/josnusd.44.73.

16. Al-Omari QD, Hamasha AA. Gender-specific oral health attitudes and behavior among dental students in Jordan. J Contemp Dent Pract 2005;6(1):107-114. DOI: 10.5005/jcdp-6-1-107.

17. Jiang $H$, Peterson PE, Peng $B$, et al. Self assessed dental health, oral health practices, and general health behaviors in Chinese urban adolescents. Acta Odontol Scand 2005;63(6):343-352. DOI: 10.1080/00016350500216982.
18. Al Shammari KF, Al-Ansari JM, Al Khabbaz AK, et al. Self reported oral hygiene habits and oral health problems of Kuwait adults. Med Princ Pract 2007;16(1):15-21. DOI: 10.1159/000096134.

19. Sen N, Mandal A, Bhat N, et al. Oral health knowledge, attitude and practices among patients attending the department of public health dentistry of a dental hospital in Udaipur India. Int J Prev Clin Dent Res 2017;4(1):43-49. DOI: 10.5005/jp-journals-10052-0079.

20. Khami MR, Virtanen Jl, Jafarian $M$, et al. Oral health behavior and its determinants amongst Iranian dental students. Eur J Dent Educ 2007;11(1):42-47. DOI: 10.1111/j.1600-0579.2007.00424.x. 